\title{
A Smartphone App to Leverage Positive Psychology to Support Smoking Cessation in Nondaily Smokers: Results of SiS Study 1
}

\author{
Bettina Hoeppner, MS, PhD; Susanne Hoeppner, PhD; John Kelly, PhD \\ Recovery Research Institute, Center for Addiction Medicine, Harvard Medical School, Massachusetts General Hospital, Boston, MA, United States
}

\author{
Corresponding Author: \\ Bettina Hoeppner, MS, PhD \\ Recovery Research Institute, Center for Addiction Medicine \\ Harvard Medical School \\ Massachusetts General Hospital \\ 151 Merrimac Street \\ Boston, MA, \\ United States \\ Phone: 6431988 \\ Email: bhoeppner@mgh.harvard.edu
}

\begin{abstract}
Background: The population of nondaily smokers is large (ie, 24.3\% of adult smokers) and increasing (ie, $27 \%$ increase over the past decade). The cancer risk of nondaily smoking is substantial (40\%-50\% of that seen in daily smokers). Existing treatments are ill-suited for nondaily smoking, because the treatments are based on nicotine dependence, and traditional treatments and treatment modalities (eg, in-person counseling, medication) do not appeal to non-dependent nondaily smokers.

Objective: We sought to develop a smartphone app that acts as a behavioral, in-the-pocket coach and uses positive psychology exercises to enhance quitting success.

Methods: Nondaily smokers ( $\mathrm{n}=30)$ used Version 1 of the "Smiling Instead of Smoking" (SiS) app while undergoing a quit attempt (1 week pre-, 2 weeks post-quit). The app assigned daily positive psychology exercises, provided smoking cessation tools (ie, scheduling quit day, logging personal reasons for quitting, planning for challenging times, enlisting social support), and made information about smoking cessation available (ie, benefits of quitting, strategies for cravings). Participants answered surveys at baseline and 2,6, and 12 weeks post-quit and participated in structured user feedback sessions 2 weeks after their chosen quit day.

Results: During the 3 weeks of 'prescribed' use, $50 \%$ of participants completed every daily positive psychology exercise, and the remaining $50 \%$ completed on average $85 \%$ of the daily exercises. Use of the user-initiated tools was limited: $20 \%$ did not use the "Challenging Times" tool at all; those who did only used it twice (median); $27 \%$ used the "Social Support" tool on multiple days. Self-reported smoking abstinence rates were 43.3\% (7-day abstinence) 2 weeks post-quit, and 40.0\% and 43.3\% (30-day abstinence) at 6 and 12 weeks post-quit, respectively. Most participants (90\%) felt the app helped them during their quit attempt, especially in terms of staying on track, giving them confidence, and reinforcing the idea that quitting was worthwhile. Usefulness ratings were particularly high for functionality that allowed participants to (re-)schedule their quit day and log their personal reasons for quitting smoking. In line with putative mechanisms underlying smoking cessation, compared to baseline, participants reported a lower urge to smoke $(\mathrm{F}(1,29)=20.55, P<.001)$, increased self-efficacy to abstain from smoking, both in response to internal $(\mathrm{F}[, 29]=12.69, P<.01)$ and external stimuli $(\mathrm{F}[1,29]=18.95, P<.001)$, decreased endorsement of the psychoactive benefits $(\mathrm{F}[1,29]=16.24, P<.001)$ and pleasure $(\mathrm{F}[1,29]=5.44, P=.03)$ of smoking, and lower perceived importance of the pros of smoking $(\mathrm{F}[1,29]=18.26, P<.001)$. Qualitative feedback indicated a desire for more variety in the positive psychology exercises, more recommended strategies for dealing with cravings, less wordy but more frequent behavioral counseling check-ins, a reward systems, and the removal of the "social support" tool.
\end{abstract}

Conclusions: A positive psychology approach to support smoking cessation resonated well with nondaily smokers. App usage of these exercises was high over a 3-week period, suggesting that this treatment approach is sustainable during the critical phase of smoking cessation. Abstinence rates were substantially higher than natural quit rates in this population, and thus offer some promise, which will need to be evaluated in a randomized trial.

(iproc 2018;4(2):e11762) doi: $10.2196 / 11762$ 


\section{KEYWORDS}

cigarette smoking; mHealth; mixed methods

Edited by T Hale; this is a non-peer-reviewed article. Submitted 01.08.18; accepted 29.08.18; published 17.09.18.

Please cite as:

Hoeppner B, Hoeppner S, Kelly J

A Smartphone App to Leverage Positive Psychology to Support Smoking Cessation in Nondaily Smokers: Results of SiS Study 1 iproc 2018;4(2):e11762

URL: http://www.iproc.org/2018/2/e11762/

doi: $\underline{10.2196 / 11762}$

PMID:

CBettina Hoeppner, Susanne Hoeppner, John Kelly. Originally published in Iproceedings (http://www.iproc.org), 17.09.2018. This is an open-access article distributed under the terms of the Creative Commons Attribution License (https://creativecommons.org/licenses/by/4.0/), which permits unrestricted use, distribution, and reproduction in any medium, provided the original work, first published in Iproceedings, is properly cited. The complete bibliographic information, a link to the original publication on http://www.iproc.org/, as well as this copyright and license information must be included. 